\title{
Contour mapping of seismic areas by numerical filtering and geological implications
}

\author{
II. Caputo (*) - I). Postpische (**)
}

Received on December 22nd, 1974

Summary. - A method is described that makes possible the identification of the independent seismic units of a given area (Caputo and I'ostpischl, $1973 \mathrm{~b})$.

The scismic information is treated as a bidimensional signal disturbed by a certain background noise. The filtering of this noise makes it possible to delineate the seismic areas objectively.

An indirect check on the methor was male by estimating with respect to the various regions identified the $\alpha$ and $\beta$ parameters of the law

$$
N_{y}=\alpha e^{-\beta_{y}}
$$

which gives the number of earthquakes with magnitude (intensity) greater than or equal to $y$.

Riassunto. - In questa nota viene descritto un metodo che rende possibile l`identificazione delle unità sismiche indipendenti di una data zona.

T. informazione sismiea è considerata come un segnale bidimensionale disturbato da un certo rumore di fondo. Filtrando detto rumore, si possono traceiare, da un punto di vista oggettivo, le aree sismiche.

Il metodo usato è stato verificato indirettamente, mediante la stima rispetto alle varie regioni identificate - dei parametri $\alpha$ e $\beta$ della legge:

$$
N_{\boldsymbol{y}}=\alpha e^{-\beta_{y}}
$$

legge che rappresenta il numero di terremoti con magnituro (intensità) maggiore o uguale a $y$.

$\left(^{*}\right)$ Istituto Nazionale di Geofisica. Roma.

$\left({ }^{* *}\right)$ Istituto di Geofisica, Universiti. Bologna. 


\section{INTRODUCTION}

Italy is part of a seismic band that is among the most active in the world and which extends from the Azores to the East to link up with the seismic system ringing the Pacific.

In recent times some disastrous earthquakes have thrown a whole nation into mourning and caused enormous damage and brought the direst poverty to populations alrearly sorely tried by the difficulties incirlental to their lives.

As regards seismic calamities it is very unlikely that any form of direst control can ever be achieved; however, the seismic history of a region enables certain parameters to be evaluated, which, suitably interpreted, may lear to the formulation of criteria of estimating the seismic risk for economic development planning.

The problem is usually approached by considering certain statistical models on the basis of which, from the seismic history of the region considered, quantitative information can be gathered regarding the probability of the occurrence of destructive tremors (Caputo et al., $1973 ; 1974)$.

The critical point in this type of investigation consists in the delineation of the regions to investigate.

In fact, the lack of precision in epicentral determinations leads to an irregular dispersion of epicentres so that these cannot often be grouperl in unambiguously delimited regions. This may lead to a distortion of the results of the statistical analysis of the events in the region, since we must expect that some of the relations implied by the chosen statistical model represent an average characteristic as the result of the superimposition of various effects corresponding to as many independent seismic units present in the region being consirlererl.

The purpose of this paper is the definition of an objective method on seismic regionalization.

There is no intention of laying down here a seismic regionalization of Italy, it is desired simply to suggest a new methor for defining it, to be used with complete catalogues of events and together with information deriving from other types of investigation such as, for example, geologically rletermined faults, the structure and composition of the crust gathered from both seismic methods and through gravimetric analysis, etc., which, it is to be hoped, can be expressed also in an analytic form. 


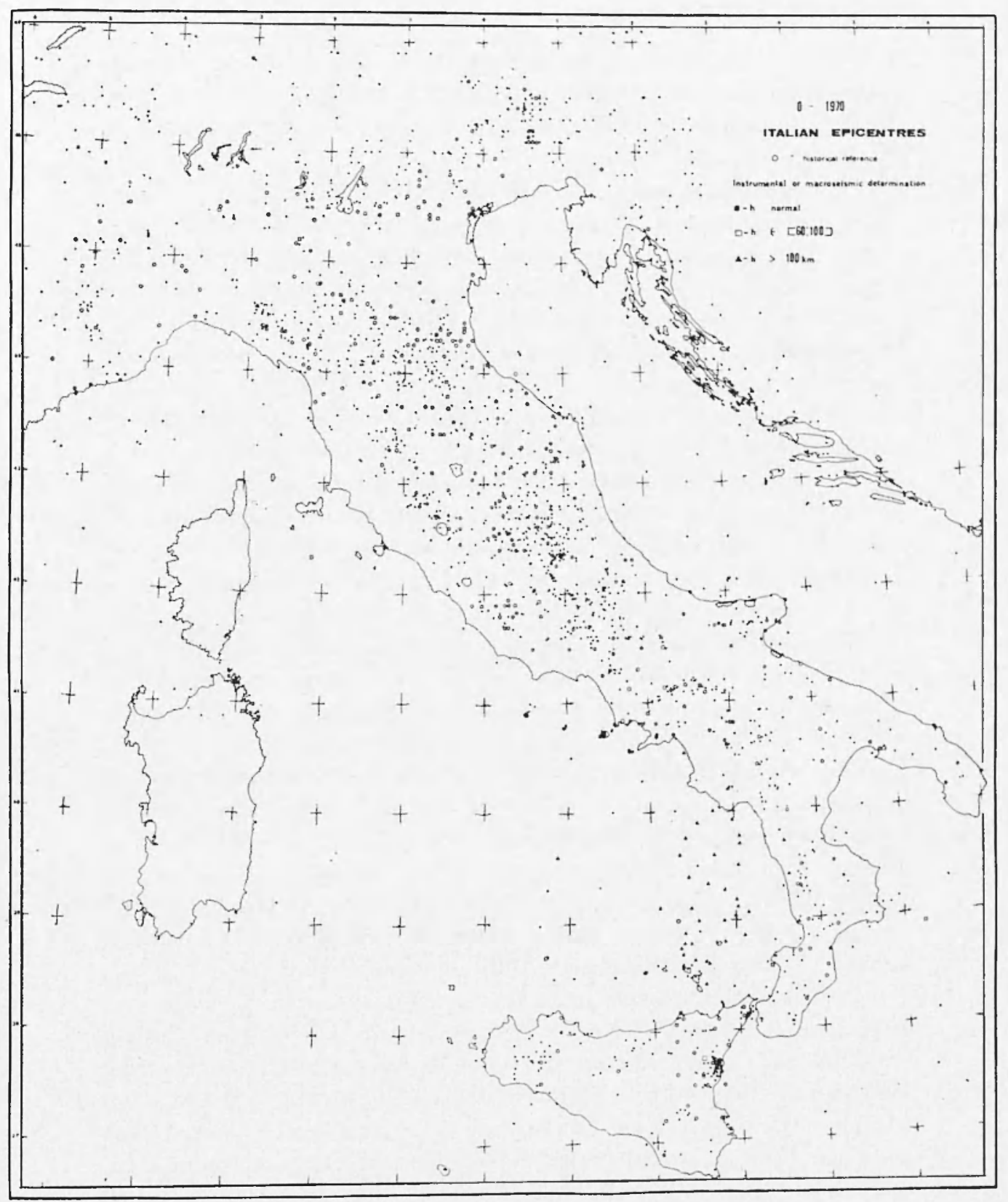

Fig. 1 - Distribution of Italian instrumental macroseismic and hystorical epicentres. 


\section{Tine IDATA}

The data utilized were taken from the Catalogue of Italian earthquakes from the year 0 to 1970 of MI. Caputo and 1). Postpischl (1972), and the corresponding epicentres are set out in fig. 1 (Caputo and Postpischl, 1972, 1973ณ).

As regards the quality of the available information, the events are grouper into four classes according to the precision of the epicentral determination (Karník 1969). We have in fact events definerl as historical for which the intensity was calculated on the basis of the descriptions in historical chronicles of the damage caused, and the epicentre is associated with the city, town or village that suffered the greatest lamage.

A second class (indicated by the letter $C$ in the catalogue) groups the instrumental events weakly determined, so that one may expect an error greater than $0.9^{\circ}$ in the epicentral retermination.

The third class (B) includes those events for which the epicentre is estimated with an error between $0.3^{\circ}$ and $0.9^{\circ}$.

Finally, the fourth class $(A)$ comprises the instrumental events for which the epicentre may be associated with an error of less than $0.3^{\circ}$.

We wish to emphasize that it is not clamed that the catalogue is complete in an absolute sense; in fact we deliberately limiter the collection to a statistically representative sample, so as to be able to set out the working method. A retailed investigation may be male later by means of the application of the above mentioned methor to a catalogue of earthquakes as complete as possible, which can be the ontcome only of the collaboration of all who are concerned at present, with the collection of seismic data in Ttaly.

In this work we have utilized only the data relative to instrumental events, grouping them in rlifferent ways in order to satisfy diverse variants as will be more fully explained below.

We have deliberately excluded earthquakes with a depth exceerling $60 \mathrm{~km}$, since the deep seismic activity affecting our region is limited to a small number of events all locater in the South Tyrrhenian sea (Caputo, Panza, Postpischl, 1970, 1972).

Moreover all those events that might be considered as aftershocks have also been eliminater from the catalogue, it being presumed that there is an aftershock when the interval of time between two events is less than a week and the distance between the epicentres is less than $10 \mathrm{~km}$ (Caputo, Keilis-Borok et al., 1973). In this way the ma- 
CONTOUR MAPPING OF SEISMIC AREAS BY XUMERTCA VILTERIXG FTC. 623

jority of aftershocks is eliminated and their closer identification is not necessaty for the purposes of this paper.

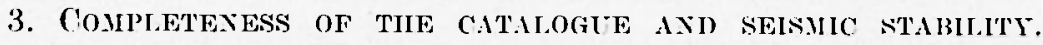

In this paragraph we analyse the catalogue of the data from the point of view of completeness, since this parameter rletermines in a significant manner both the results of a regionalization study and the results of a statistical analysis rlirecter to the evaluation of the return periorls and of the seismic risk.

Obviously one may expect that for each region events with larger magnitude should have more probability of being present in the catalogne, also that the probability is a decreasing function of time counted backwarls from the end of the catalogue. For these reasons one should establish the time interval for which all the events of at fixed magnitude which actually occurred are recorded; this leads to the retermination of a function:

$$
M=f(t), \quad f^{\prime}(t)<0
$$

where $t$ is the lower bound of that interval. Practically, for the Italian catalogue we drew two by two matrix shown in Table 1, where the

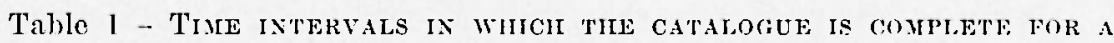
FIXED IACNITUDE.

\begin{tabular}{|c|c|c|c|c|c|c|c|c|c|c|}
\hline \multirow{2}{*}{ Years } & \multicolumn{9}{|c|}{$\operatorname{lnt} \cos \mathrm{st} y$} & \multirow{2}{*}{ Total } \\
\hline & 3 & 4 & 5 & 6 & 7 & 8 & 9 & 10 & 11 & \\
\hline 1885 & 3.0 & 4.0 & 1.0 & 23.5 & 19.0 & 4.0 & 2.5 & 0.0 & 0.0 & 57.0 \\
\hline 1890 & 5.0 & 3.0 & 3.0 & 19.0 & 9.0 & 4.0 & 2.0 & 1.0 & 0.0 & 46.0 \\
\hline 1895 & 0.0 & 1.0 & 3.5 & 43.5 & 29.5 & 9.5 & 3.5 & 0.5 & 0.0 & 91.0 \\
\hline 1900 & 10.5 & 9.5 & 5.0 & 45.5 & 14.5 & 6.5 & 1.5 & 0.0 & 0.0 & 93.0 \\
\hline 1905 & 2.0 & 17.0 & 11.5 & 73.0 & 36.5 & 8.5 & 4.5 & 0.0 & 1.0 & 154.0 \\
\hline 1910 & 3.0 & 11.0 & 16.0 & $1+4.0$ & 48.5 & I I.5 & 3.0 & 1.0 & 1.0 & 239.0 \\
\hline 1915 & 0.0 & 3.0 & 0.5 & 81.5 & 20.0 & 2.0 & 2.0 & 2.0 & 0.0 & 111.0 \\
\hline 1920 & 27.0 & 33.0 & 28.0 & 56.5 & 26.5 & 7.5 & 3.0 & 1.5 & 0.0 & 183.0 \\
\hline 1925 & 2.5 & 11.0 & 16.5 & 57.5 & 18.0 & 3.5 & 0.0 & 0.0 & 0.0 & 109.0 \\
\hline 1930 & 23.5 & 53.0 & 26.5 & 58.0 & 15.5 & 3.5 & 2.5 & 1.5 & 0.0 & 184.0 \\
\hline 1935 & 8.5 & 18.0 & 22.0 & $33 . \overline{5}$ & 15.0 & 1.0 & 1.0 & 0.0 & 0.0 & 100.0 \\
\hline 1940 & 2.0 & 13.5 & 18.5 & 43.0 & 12.5 & 6.5 & 1.0 & 0.0 & 0.0 & 97.0 \\
\hline 1945 & 4.5 & 11.0 & 14.5 & 21.0 & 11.5 & 1.5 & 1.0 & 0.0 & 0.0 & 65.0 \\
\hline 1950 & 2.5 & 9.0 & 11.5 & 34.5 & 16.5 & 5.11 & 1.0 & 0.0 & 0.0 & 80.0 \\
\hline 1955 & 15.0 & 32.5 & 50.5 & $3(j .5)$ & 12.5 & 2.0 & 0.0 & 0.0 & 0.0 & 149.0 \\
\hline 1960 & 105.0 & 118.0 & 90.5 & 41.5 & 18.5 & 2.5 & 0.0 & 0.0 & 0.0 & 408.0 \\
\hline 1965 & 59.0 & 123.5 & $6+.0$ & 46.5 & 12.5 & 9.5 & 1.5 & 0.0 & 0.0 & 351.0 \\
\hline 1970 & 60.0 & 80.0 & 47.5 & 29.0 & 0.0 & 5.0 & 2.5 & 0.0 & 0.0 & 266.0 \\
\hline
\end{tabular}


heavy line gives the time interval in which the catalogue is complete for a fixed magnitude. The line has been drawn consirlering for each magniturle a subdivision of the catalogue in a set of equal time interrals of such lengths as to contain a suffieient number of events (therefore not necessarily the same length for all the magniturles) and defining the time where there is a sharp and stable change in the number of events for each interval. Luckily, there has never been any doubt in establishing this time. In the Table 1 the length of the interval has then been standarlizer for all mannitures for the sake of simplicity of presentation. Repenting this procerlure for each seismic region, we can therefore assume that in Italy in the periods in which the atalogue was completer, for each magniturle there was stability in the seismic activity.

Obviously these criteria could be formulated more aceurately from a statistical and mathematical point of view, for instance, to establish the confirence level of the statements, to determine more accurately the intervals of completeness of the catalogue, etc.

\section{RECIONALIKATION}

We wish to propose a completely objective method of seismic regionalization and one with a regree of reliability that is directly proportional to the quantity and quality of the available information.

In the case of seismic events the available information is found to be very weak. We must in fact take into account at least two types of errors that are usually the cause of considerable distorsion in the seismic picture of a region:

a) incompleteness of the data for events belonging to the lower end of the scale of magniturle;

b) errors in the determination of the epicentres and of the focal (lepth.

The a) type of errors depends essentially on the insufficience and on the distribution of the elements of the existing Italian seismic network. The b) type of errors is to be attributed both to the causes alrealy mentioned and to the lack of correct travel-times for Italy.

It must be emphasized that the structure of the crust and the upper mantle of the Meditermanean basin, and above all in the area 


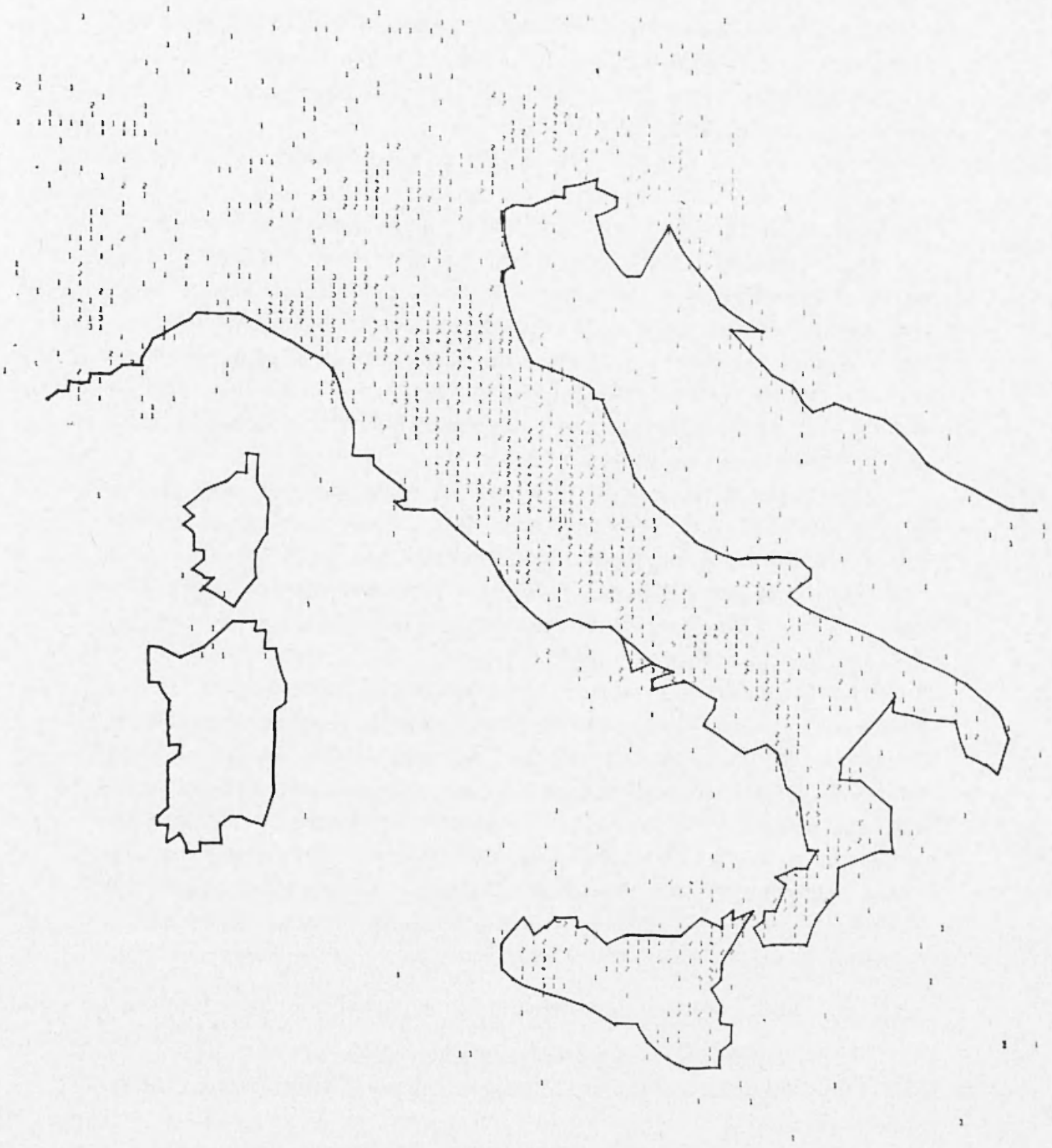

Fig. 2 - Frequencies of the occurrence of earthquakes for each element of a grid of $\sim 10 \mathrm{~km}$ side, after elimination of aftershocks. 
of the Appennines, even though not yet known in detail, present highly diflerentiated characteristics.

The general seismic picture resulting from the sum of these two types of errors is considerably distorted, in particular the dispersion of the epicentres learls 10 a multiply of possible solutions to the problem of regionalization.

In our opinion the problem can be reduced within certain limits to a problem of birlimensional filtering.

In fact in the case of a sufficiently large statistical sample, we can think of the distribution of the epicentres as a bidimensional signal distorted by a certain casual background noise. The problem is therefore reduced to the filtering of this noise. Obviously, there is not a perfect parallel, in fact the causes of the $a$ ) and $b$ ) types of errors do not theoretically lean to a purely casual distortion, and as it has been stated above some systematic eflect must be almitter, due to the special structure of the crust.

This type of error is to be regarded as systematic, and only a greater knowledge of the structure of the crust and upper mantle can lean to its being reduced to a minimum. As regards the stochastic element in the distortion, this may be partly removerl by using suitable filters. The question of the optimum filter for this type of research was not treated.

The avalable information was distributed over a grid with a $10 \mathrm{~km}$-sided mesh, and a count was mate of the frequency of the epicentres for each element of the network, a diflerentiation being marle both with respect to the classes of epicentral determination and with respect to the value of the intensity of the events. The choice of $10 \mathrm{~km}$ as the width of the mesh was decided upon simply because of the necessity of having a certain number of events for each element in the network in the seismic areas and because the errors in epicentral coorlinates are of this rate.

The research was begun with the following cases being consiclered:

1) Complete catalogue of instrumental events

2) Complete artalogue of instrumental events without aftershocks (fig. 2)

3) Catalogue of $A$ and $B$ class instrumental events

1) Catalogue of $\Lambda$ class instrumental events

5) Catalogue of instrumental events $I \geqslant$ VII

6) Catalogue of instrumental events $I \geqslant I X$ 
In all these cases a normal low-pass bidimensional filter (BozziZadro and Capnto, 1968) was applied, both the cut-off frequency $f_{c}$ and the number of weights being varied from time to time. The weights of the filter are:

$$
\begin{gathered}
\omega_{i j}=\omega_{j i}=\omega_{-i j}=\left(\omega_{i-j}=()_{j-i}\right. \\
\omega_{i j}=V_{i} V_{j} \\
V_{i}=f(i) / \beta, \quad \beta=f(0)+2 \sum_{n=1}^{I} f(n) \\
f(i)=\frac{2(I+1)}{\pi i^{2}} \sin \left(\pi f_{c}\right) \sin \frac{\pi i}{I+1} \quad f(0)=2 f_{c}
\end{gathered}
$$

The total number of the weights is $(2 I+1)^{n}$; that is $|i| \leqslant I$.

It was thus possible to establish that an optimization of the filter is achieved in our case with a cut-ofl frequency $f_{c}=1 / 4$ (expressed in Nyquist units), with $I=10$. Tests were made considering $I=-5$, $I=10$ and $I=25$. The passage from $\tilde{5}$ to 10 is significant in the sense that there is a better definition of the areas corresponding to zones where the information is greater and a smoothing of the signal in those areas where the information is weaker. The step from 10 to 25 does not produce significant improvements.

The application of the filter to the cases 1 to 6 indicated above makes it possible to identify certain seismic units. In fig. 3 the result is shown of the application of the filter to the catalogue of instrumental events without aftershocks. This was regarded as the principal case; the other variants were utilized as a check on the solution illustrated in fig. 3. By way of example, there are shown in fig. $t$ the results of filtering applied to the catalogue of only class $A$ and 13 events, and in fig. 5 the results of the application of the filter to the catalogue without aftershocks, but considering a cut-ofi frequency $f_{c}=1 / 12$ in Nyquist units.

In this way it is possible to trace the contouls of some inclependent seismic units. Each of these units can in its turn be subdivided into two or more subregions, in accordance with a predetermined pass.

Considering these units from a physical point of view, if the filter has really separated independent seismic units, then for each of these the mechanism of the earthquake should be found constant, while the seismicity should decrease as one proceeds from the innemost towards the outermost zones of the seismic unit considered. This 
type of analysis is indirectly possible through the evaluation of the $a$ and $\beta$ pallameters of the lat

$$
N_{y}=\alpha e^{-\beta_{y}}
$$

which gives the number of earthquakes with magnitude (intensity) $I \geqslant y$.

The a parameter depends on the level of the seismic anctivity per unit of time and area (Isacks and Oliver, 1964; Karnik, 1966), and therefore, especially in our case, it should be decreasing as one proceeds from the innermost to the outermost zones of a seismic unit.

As regards the $\beta$ parmeter, there is evidence that this depends largely on the stress, the strain and the homogeneity of the rocks in the focal area (Mogi, 1963) or also on the average lepth of the earthquakes consiclered (Karník, 1966; Galanopoulos, 1968-1971).

For a given geotectonic unit there are no significant variations in $\beta$ in relation to time or the number of shocks (Isacks and Oliver, 196.1; Miyamula, 1962; Riznichenco and Nersessov, 1968).

For these reasons we estimated the values of a and $\beta$ for ench seismic unit identified by the filter. The results obtained are listed in Table 2 and ane to be referred to the regions indicated in fig. 6 , which was obtained from fig. 3.

For many of the regions illustrated in fig. 6 , the particular sample of available events would have alled for the application of highly sophisticated methods to obtain estimates of $\alpha$ and $\beta$, and in all cases these would have been somewhat uncertain. For these reasons we limited ourselves to the investigation of those regions that allowed a realistic estimate to be made, by means of Gumbel's method (Gumbel E. J., 1958; Lomnit\% G., 1966).

The analysis of the Table 2 enables the following considemations to be made.

\section{1. - A, B, ( R.GGrons}

The statistics relative to these regions are too weak to permit a significant estimate to be mate of the $\alpha$ and $\beta$ parameters.

\section{2. - D REGION}

Tn this case, on the basis of values supplied by the filtering, we were able to extend the sublivision to a maximum of four subregions 
D1, D2, D3, D4, each contained within the successive one. The values of $\alpha$ normalized as to unit of area and mit of time are decreasing as one proceeds from the innermost towarls the outermost areas, when the subregions are considered as having a ling structure D2-I)I; I)3-I): D4-D3. The estimaterl values of $\beta$ tend on the contray to remain constant. The test of the hypothesis $H_{\mathrm{o}}: \beta_{i}=\hat{\beta}$ against the alternative $H_{1}: \beta_{i} \neq \hat{\beta}, i=1,2,3$, is here acceptable.

\section{3. - E REGION}

This area covers the most active region in Italy from a seismic point of view. Also from a geotectonic standpoint the area is the site of remarkable phenomena; it is in fact traversed by the Anzio-Ancona tectonic line, and it is, besides, fractured into a consirlerable number of superficial faults (Malaroda and Raimondi, 1957). The clata griven by the filtering enabled us to divide this region into eight subregrions. It is not possible to extend the subdivision further since the statistics relative to the various rings J3-L2; E4-E3; E6-Lo; ET-E6; ES-Et become too weak.

In this case F2-F1 does not appear, since the E1 subregion does not by itself make possible an estimate of the parameters.

The test of the hypothesis $H_{0}: \beta_{i}=\hat{\beta}$ against the altemative hypothesis $H_{1}: \beta_{i} \neq \hat{\beta}, i=1,2,3,4,5,6$ gives an acceptable response.

However the rapid increase in the $\mid \beta$ values for ET-E6 and Es-Et suggests the theory that there are includer, with the It and Es areas, events belonging to a new seismic unit independent of the first, not identifier by the filter because of insufficient information, but distinguished later through the estimate of the $\alpha$ and $\beta$ parameters of the law [1] for the different subregions.

As we have already said the $\mathbf{E}$ region is traversed by the AnzioAncona tectonic line, which also separates structures of different homogeneity, in particular the more Northerly structures are more fissured than those South of the line (Malaroda and Raimondi, 1950). This fact suggests the entting of the ET and Es areas along the AnzioAncona line (see figr. 7). Tn this way the values indicated by VET-E6 and VES-VET are obtained (VES and VET are the new areas derived from ET and E8). As can be seen, the variant VET-E6 leads to values in the estimate that are fully compatible with those obtained for the inner areas. Also the $95 \%$ confidence interval of the considered para- 
meter's for the VET-E6 and VE8-VET sublivisions are better than those of ET-E6 and ES-ET subrlivision.

An analysis of the structure of the VES region shows that it stretches towards the West with a lateral branch to embrace a zone involved in superficial vulamica phenomena. We therefore tried a new variant (VTES) of exchuling this tail from the VES region. The result was what had been expected, the estimate of $\beta$ for the VVE8VET area was found immerliately to be compatible with the $\beta$ estimates obtained for the innermost areas.

Table 2 - a AND $\beta$ ESTIMATES OF THE paraveTERS OF THE LAW [1] (SER THE TEXT); $A$ ln $\alpha$ AXD $A \beta$ ARE 95\% CONFIDENCE INTERVAts of lin $\alpha$ AND $\beta$.

\begin{tabular}{|c|c|c|c|c|c|}
\hline Region & $\ln \alpha$ & $\alpha /(\mathrm{Q} . \Delta t)$ & $\beta$ & $\pm 1 \ln \alpha$ & $\pm \Delta \beta$ \\
\hline $\begin{array}{l}\text { 1) } 2-1) 1 \\
1) 3-1) 2 \\
\text { 1) } 4-1) 3\end{array}$ & $\begin{array}{l}2.98 \\
3.07 \\
3.19\end{array}$ & $\begin{array}{l}0.13 \\
5.92 \\
1.33\end{array}$ & $\begin{array}{r}-0.58 \\
-0.58 \\
-0.63\end{array}$ & $\begin{array}{l}4.9 \\
1.1 \\
2.0\end{array}$ & $\begin{array}{l}0.82 \\
0.18 \\
0.33\end{array}$ \\
\hline $\begin{array}{l}E 3-E 2 \\
E 4-E 3 \\
E 5-E 4 \\
E 6-E ; 5 \\
E 7-E 6 \\
1: 8-1: 7\end{array}$ & $\begin{array}{l}2.96 \\
3.15 \\
3.18 \\
5.52 \\
5.04 \\
4.39\end{array}$ & $\begin{array}{r}13.74 \\
12.66 \\
8.12 \\
6.81 \\
22.43 \\
6.10\end{array}$ & $\begin{array}{r}-0.57 \\
-0.62 \\
-0.66 \\
-0.63 \\
-0.83 \\
-0.77\end{array}$ & $\begin{array}{l}0.6 \\
0.7 \\
0.9 \\
1.3 \\
1.6 \\
2.3\end{array}$ & $\begin{array}{l}0.09 \\
0.12 \\
0.15 \\
0.19 \\
0.24 \\
0.36\end{array}$ \\
\hline $\begin{array}{c}\text { VET-E6 } \\
\text { VER-VE7 } \\
\text { VVE8-VE7 } \\
\mathrm{Q}_{3} \\
\mathrm{R}_{3}\end{array}$ & $\begin{array}{l}3.31 \\
4.55 \\
2.98 \\
1.88 \\
4.68\end{array}$ & $\begin{array}{r}1.90 \\
8.90 \\
2.76 \\
0.98 \\
19.24\end{array}$ & $\begin{array}{r}-0.62 \\
-0.81 \\
-0.63 \\
-0.36 \\
-0.67\end{array}$ & $\begin{array}{l}1.1 \\
2.3 \\
1.2 \\
0.4 \\
2.3\end{array}$ & $\begin{array}{l}0.18 \\
0.35 \\
0.21 \\
0.06 \\
0.29\end{array}$ \\
\hline
\end{tabular}

The method is therefore working on two levels; in the first stage an analysis is made of the purely geometric distribution of the epicentres being considered; while in the second stage, consideration is given to the physical nature of the shocks and other geophysical aspects of the problem are involved. In particular, what escapes analysis at, the first level is brought to light at the second stage of the investigation and can be included in the analysis by having recourse to the supplementary information that can be got from our store of geophysical and geological information relative to the region being investigater. 


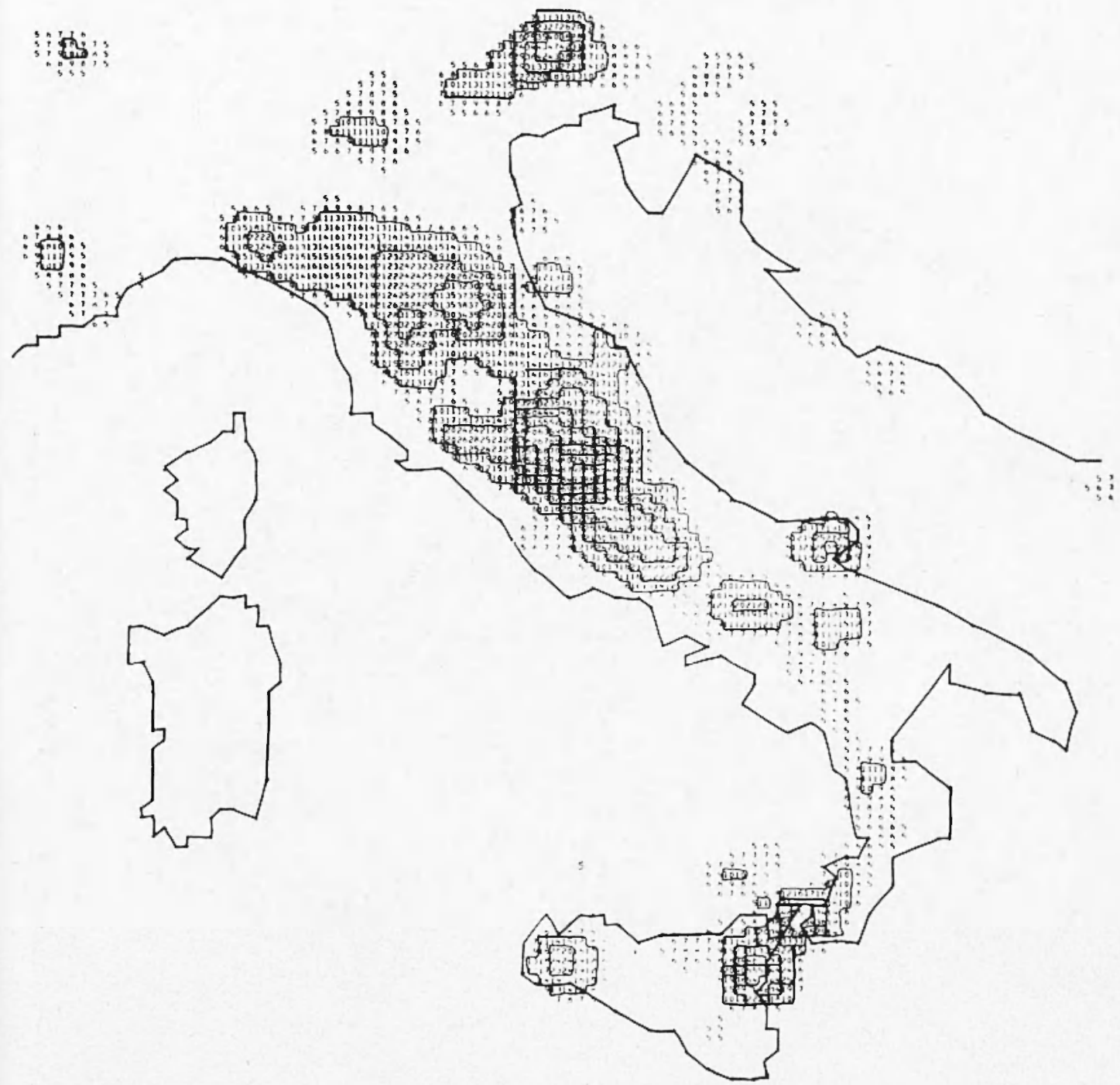

Fig. 3 - Seismic regionalization obtained by the application to the data of firr. 2 of a low-pass bidimensional filter with a cut-off frequencies $f_{c}=1 / 4$ (in Nyquist units). 


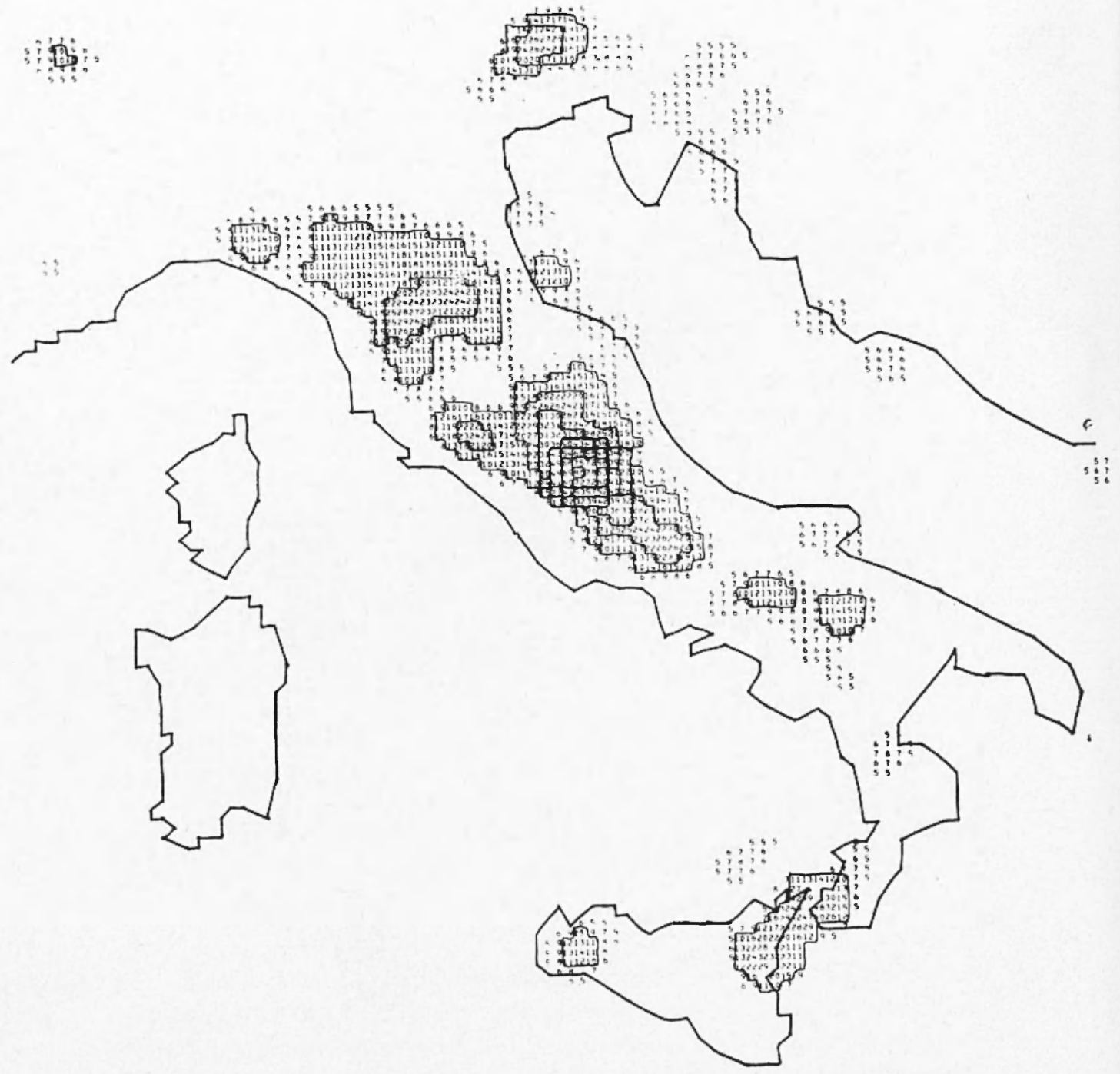

Fig. 4 - Seismic regionalization obtained by filtering the data relative to events of epicentral class $A$ and $B$ only $\left(f_{c}=1 / 4\right.$, in Nyquist mits). 


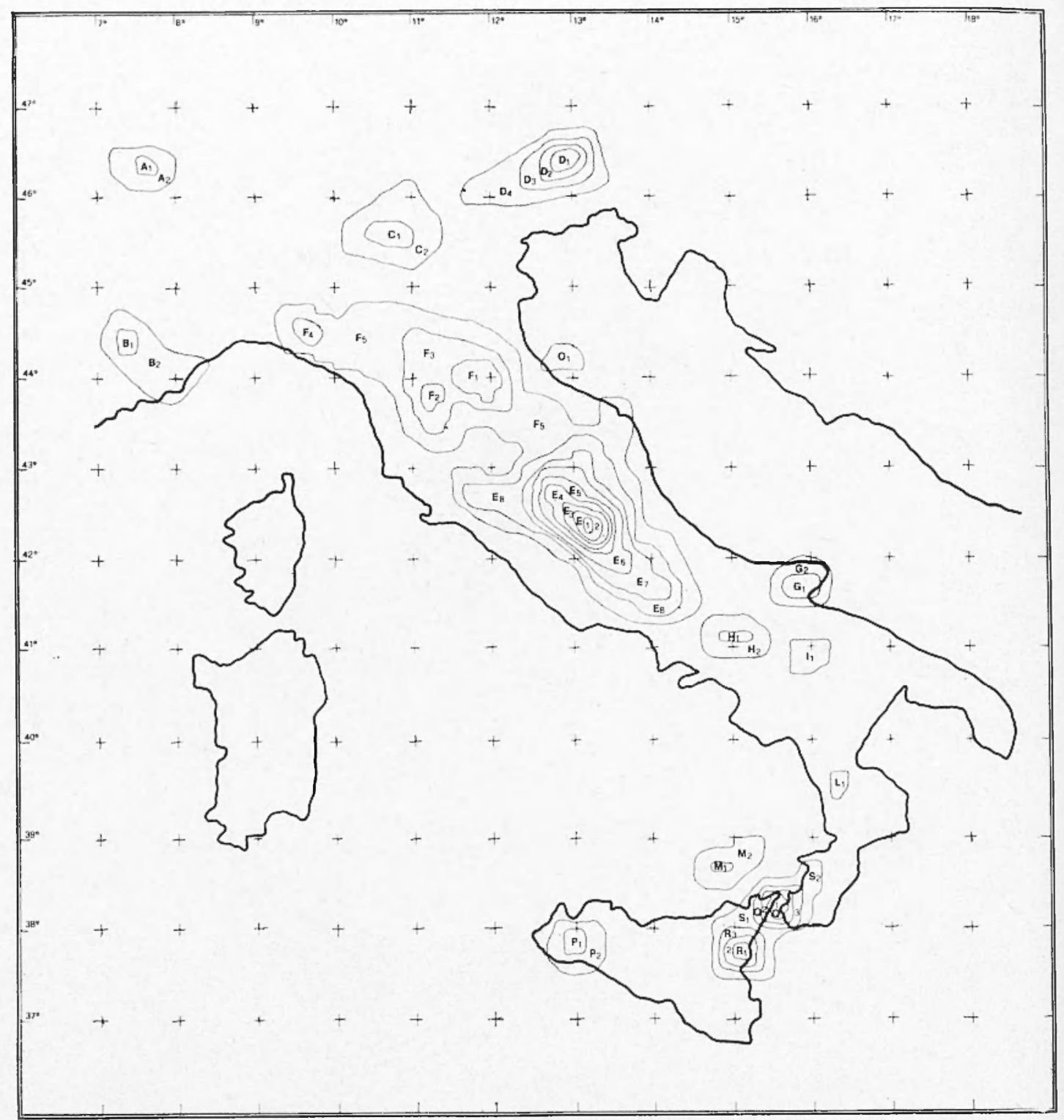

Fig. 6 - Regions and sub-regions considered for the determination of the $\alpha$ and $\beta$ parameters of the law $N_{y}=\alpha e^{-\beta_{y}}$ (see the text). 
CONTOUR MAPPING OF SEISMIC AREAS BY NUMERICAL, FILTERING ETC, 635

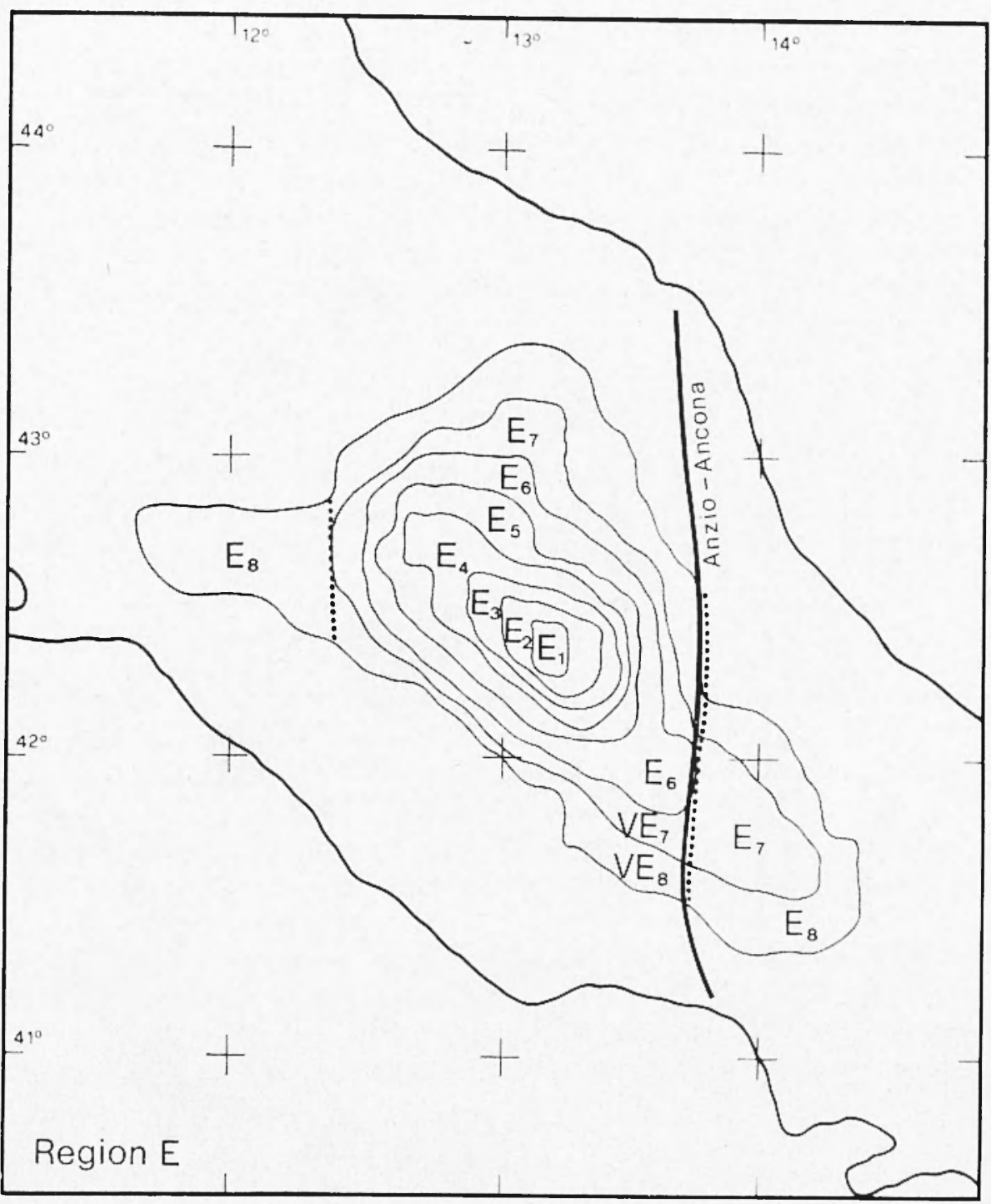

Fig. 7 - Region E. Variants VE7 and VE8 (see the text). 


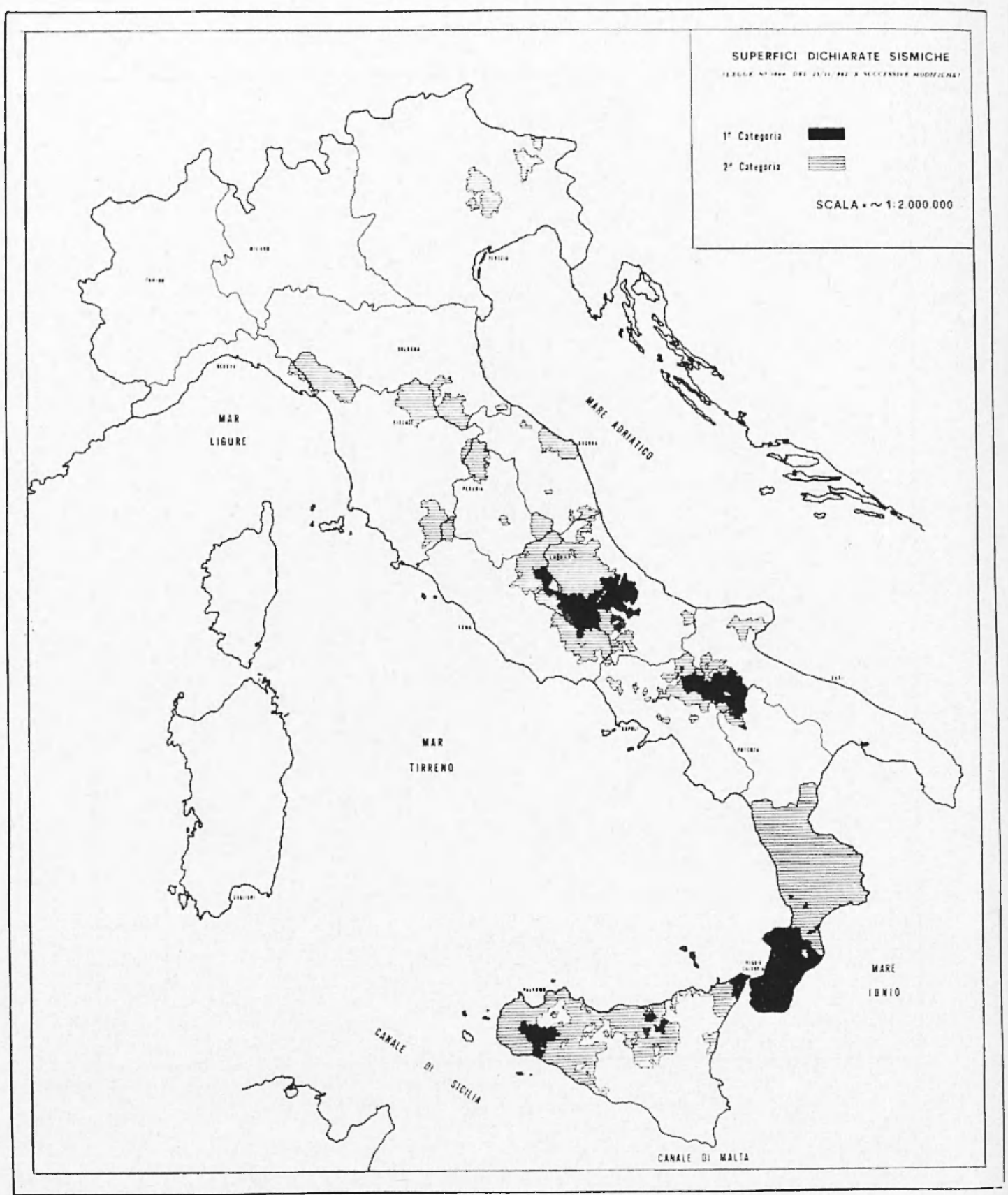

Fig. 8 - Italian seismic law of 25/11/1962. 


\section{4. - F REGION}

We included under this denomination various areas that wore independent but weakly delineated by filtering.

The F5 area in particular covers a really extensive surface and extends to link up with the varions seismic units described above. It is interesting to note how the Fon region stretches out an extension to embrace the Ancona zone, the site of the more recent disastrous seismic periods involving our country. The data from which Fo was complied did not include this latter seismic period; however, an indication of the presence of this seismic unit was brought out by the filter.

\section{5. - (, , I, I, L, O, P, M. Regrons}

In this case the filter elearly delineates a seismic mit, the statistical sample does not however enable a significant estimate of the $a$ and $\beta$ parameters to be made.

\section{6. - Q, R, S. Regions}

With these regions once again find ourselves discussing areas of special geotectonic interest. The filtering shows a diffused elongater S area following the Comiso-Messina tectonic line (Ogniben, 1969) in the interior of which there appear two centres of seismic activity. Oneof these is indicated by the letter $Q$, and is centred on the Straits of Messina, the other is indicated by $R$ and is centred further South in the neighbourhood of Etna.

The filtering of the data enabled both the $Q$ and $R$ regions to be subdivided into three subregions.

The $\beta$ values in the two cases are significantly diflerent and indicate in this way a diflerent physical nature for the events belonging to the two regions.

\section{Conclusions}

The exposed example shows one of the possibilities deriving from the application of modern numerical methorls to original field studies. 
In our case the numerical methor selected seems to be particularly effectual, in fact it surpasses the objective of purely numerical zoning, becaming sonrce of geologic and geophysical information.

In this work, although original, we do not pretend to give final results, we test only the possibilities involver in the new methorlology. Of conrse, lefinitive results, more significant in the statistical sense, could derive from the application of the exposed method to a more complete collection of datis.

Though our results are to be considered provisional, a comparison with the geological knowledge (Modello strutturale d'Italia, 1973), confirms the validity of the method proposed. Moreover the comparison with the Italian Seismic law of 1962 , puts in evirlence that discrepancies are not big, and suggests the opportunity of more detailed studies that can derive only from the cooperation of the scientists that actually are involved in this problem.

\section{REFERENCES}

Bozzi Zadro M., Caputo M., 1968. - Fillri mullidimensionali e loro applicazioni geofisiche. "Annali di Geof.", XXI, 3, pp. 287-304.

Caputo MI., Paxza G. F. and Postpischl D., 1970. - Deep struchure of the Medilerranean. Basin. "J. Geophys. Res.", 75, 4919-4923.

(Aaputo M., Paxza G. F. and Postpische D., 1972. - New evidences aboul the deep structure of the Lipari arc. "Tectonophysies", 15, 219-231.

Caputo 11. and Postpiscit. 1)., 1972. - Lalian earlhquakes from the year 0 up to 19ro. Internal report. Institute of Geophysies, Dniv. Bolognit.

(aputo M. and Postpiscul I)., 1973a. - Seismicily of the Italian Region. to be published in "La ricerea Scientifien", quaderno n. 90.

Caputo II. and Postpiscit, 1)., 1973b. - Numerical seismic zoning and seismic slability. Report of the Institute of Creophysies, Lniversity of Bologna. See also abstract of the General Assembly IASIEI, Lima.

Caputo M., Kembe-Borok V. I., Kronkod T., Molchax G., Paxza G. F., Piva A., Poigaetskaja V., Postpiscile D., 1973. - Lodel of earthqualie occurrence and isoseismals in Ilaly. "Ann. di Geof.", XXVI. $2-3, \mathrm{pl}, 421-444$.

Caputo M., Keilis-Borok V. I., lironkod T., Molchas (t., l'axza (t. F., Piva A., Pongatetskaja V., Postpiscin, D., 1974. - The estimation of seismic risk for Central Ilaly. "Annali di Geofisica", XXVII, I,2.

Gamaxopoudos G. A., 1968. - On Quantilative determination of earlhqualie risl. "Ann. di Geof.", XXI, 2, 1). 193-206. 
Galanopotios G. A., 1971. - Minimum and Marimum magmilude threshold in the area of Allica, Greece. "Ann. di Geof.", XXIV, 1, pp. 29-54.

Gumber A. E. J., 1958. - Statisties of ertremes. Columbia University Press, New York.

Isacks B. and OLIVER J.. 1964. - Seismic wares with frequencies from 1 to 100 C'ycles per second recorded in a deep mine in. Sorthern Nen Jersey. "Bull. Seism. Soc. Am.", 54. pp. 1941-1979.

KÁххік V., 1966. - Magnitude. Frequency lielation and seismir artivily in. difierent regions of the European area. "Travanx de l'Inst. Geoph. de l'Acad. 'T'hécoslovaque des Sciences". 13 (222), pp. 247-272.

KÁrхí V., 1969. - Seismicily of the European. Area. Vol. 1, Reidel, Dordrecht (Holland).

Lomstтz G., 1966. - Stalistical P'rediction of Earlhquates. "Reviews of Geophysies", 4, 3.

Malaroda R. and Ramondi (., 1957. - Le linee di faglia e di scorrimento in Italia. "Boll. di Geod. e Sc. Allini", XVI, 3, pp. 273-323.

Mryamua S., 1962. - Magnitude-Frequency Relations and olher Bearings to Geolectonics. "Proc. Japan Ac.", 38. 1, pp. $27-30$.

Modello strutturale dItalia, 1973. Carta 1 : 1000000. Consiglio Nazionale delle Ricerche, Romia.

Moni K., 1963. - Study of elastic shocks caused by the fracture of heterogeneous malerials and its relation to earlhquale phenomena. "Bull. Earthq. Res. Inst.", 40, pp. 125-173, 831-853:41, pp. (615-668.

Orxinex 1., 1969. - Selema introdullivo alla Geologia del Confine Calabro. Lucano. "Mem. Soc. Geol. Ital.", 8, pp. 453-763.

Riznicienco J. V. and Nersessov I. L., 1968. - A detailed sludy of the seismic region in the Garm epicentrat region. "Ann. di Geof.", XIV, 2, pp. 287-304. 